\title{
Clinical and Echocardiographic Characteristics of Acute Cardiac Dysfunction Associated With Acute Brain Hemorrhage - Difference From Takotsubo Cardiomyopathy -
}

\author{
Mirae Lee, MD; Ju Hyeon Oh, MD, PhD; Kyung Been Lee, MD; \\ Gu Hyun Kang, MD; Yong Hwan Park, MD; Woo Jin Jang, MD; \\ Woo Jung Chun, MD; Sang Hyuk Lee, MD; In Chang Lee, MD
}

\begin{abstract}
Background: Cardiac dysfunction (CD) associated with brain hemorrhage is similar to that with takotsubo cardiomyopathy but still not well understood. We aimed to investigate the clinical and echocardiographic findings of acute $C D(A C D)$ related to brain hemorrhage.
\end{abstract}

\begin{abstract}
Methods and Results: Between 2013 and 2014, consecutive patients diagnosed with spontaneous and traumatic brain hemorrhage were prospectively enrolled. Electrocardiography, cardiac enzymes, and echocardiography were performed. Left ventricular (LV) systolic dysfunction on echocardiography was defined as ACD related to brain hemorrhage when all the following conditions were satisfied: abnormal ECG and cardiac troponin level, LV wall motion abnormality or decreased LV systolic function on echocardiography, and no previous history of cardiac disease. Otherwise, LV dysfunction was considered to be other CD unrelated to brain hemorrhage. In a total of 208 patients, $15(7.2 \%)$ showed ACD. Of them, 8 patients were men and 8 showed apex-sparing LV hypokinesia and 9 died in hospital. Other cardiac abnormalities observed in the study patients were NT-proBNP elevation $(n=123)$, QT interval prolongation $(n=95)$, LV hypertrophy $(n=89)$, and troponin I elevation $(n=47)$. There were 36 in-hospital deaths (17.3\%). Glasgow coma score and ACD were independently associated with in-hospital death.
\end{abstract}

Conclusions: ACD was observed in patients with various brain hemorrhages. Unlike takotsubo cardiomyopathy, high proportions of male sex, apex-sparing LV dysfunction, and in-hospital death were observed for ACD associated with brain hemorrhage. (Circ $J$ 2016; 80: 2026-2032)

Key Words: Hemorrhagic stroke; Neurocardiology; Neurogenic stress cardiomyopathy; Takotsubo cardiomyopathy

C ardiac injury and dysfunction after subarachnoid hemorrhage (SAH) is well recognized since it was first described. ${ }^{1-4}$ In addition, cardiac dysfunction (CD) associated with other forms of brain hemorrhage, non-hemorrhagic stroke, or acute head injury has also been reported. ${ }^{5-7}$ This type of $\mathrm{CD}$ has been referred to as neurogenic stress cardiomyopathy (NSC), takotsubo cardiomyopathy (TTC), neurogenic stunned myocardium, and neurocardiac injury., ${ }^{4,9}, 9$ The various names are indicative of the ongoing lack of understanding about $\mathrm{CD}$ associated with central nervous system events despite many previous studies.

\begin{abstract}
Editorial p 1905
NSC has similar pathophysiology and natural course to TTC..$^{8,9}$ Catecholamine-induced cardiac injury and myocardial contraction band necrosis are the main pathophysiology and pathological changes shared by TTC and NSC. ${ }^{10-13}$ According to the Japanese guideline for the diagnosis of TTC, NSC is excluded from the diagnosis and described as takotsubo-like myocardial dysfunction with cerebrovascular disease. ${ }^{14}$ However, neither the clinical nor the echocardiographic characteristics and diagnostic criteria for NSC have been well identified.

Therefore, the objective of this study was to investigate the
\end{abstract}

Received April 22, 2016; revised manuscript received June 1, 2016; accepted June 6, 2016; released online July 5, 2016 Time for primary review: 13 days

Division of Cardiology, Department of Medicine (M.L., J.H.O., K.B.L., G.H.K., Y.H.P., W.J.J., W.J.C.), Department of Neurosurgery (S.H.L., I.C.L.), Samsung Changwon Hospital, Sungkyunkwan University School of Medicine, Changwon-Si, Gyeongsangnam-Do, Republic of Korea

Mailing address: Ju Hyeon Oh, MD, Department of Internal Medicine, Samsung Changwon Hospital, Sungkyunkwan University School of Medicine, 158 Palyoung-ro, MasanHoiwon-gu, Changwon, 630-723, Korea. E-mail: mccoyojh@gmail.com

ISSN-1346-9843 doi:10.1253/circj.CJ-16-0395

All rights are reserved to the Japanese Circulation Society. For permissions, please e-mail: cj@j-circ.or.jp 


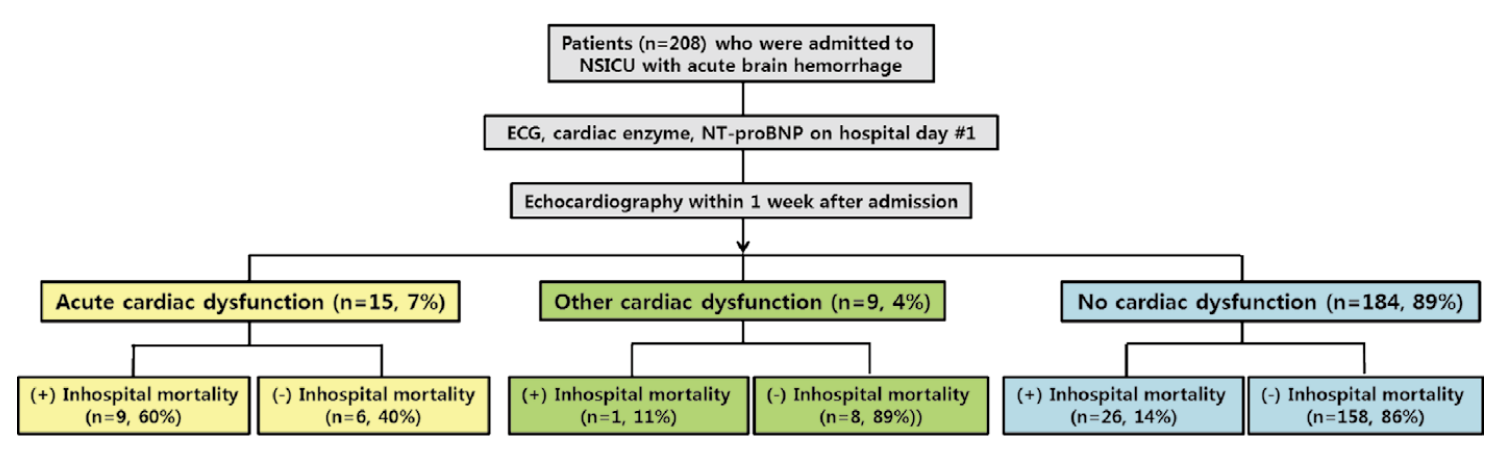

Figure 1. Study flow diagram. NSICU, neurosurgical intensive care unit; NT-proBNP, N-terminal of the prohormone B-type natriuretic peptide.

incidence and the clinical and echocardiographic findings of $\mathrm{CD}$ occurring in patients with acute brain hemorrhage. We also aimed to evaluate the clinical characteristics of $\mathrm{CD}$ related to brain hemorrhage compared with TTC.

\section{Methods}

\section{Study Population}

From March 2013 to February in 2014, consecutive patients diagnosed with acute spontaneous or traumatic brain hemorrhage and admitted to the neurosurgical intensive care unit (NSICU) were prospectively enrolled. ECG, cardiac enzymes, and N-terminal prohormone brain natriuretic peptide (NTproBNP) were checked on the day of admission, and echocardiography was performed within 1 week of admission in all patients (Figure 1). Follow-up examination for the initial tests and coronary examination were not included in the study protocol and the decisions were made by the neurosurgeon in charge of each patient or the cardiologists consulted for the patient. Clinical characteristics, laboratory findings, and inhospital outcome were collected by electronic chart review. This study was approved by the ethical committee of the Institutional Review Board at the hospital and the requirement of informed consent was waived.

\section{Definitions}

CD was defined as left ventricular (LV) systolic dysfunction showing decreased ejection fraction (EF) or regional wall motion abnormality (RWMA) on echocardiography. Abnormal cardiac enzymes or ECG in patients showing normal LV systolic function and normal LV wall motion on echocardiography was not considered as $\mathrm{CD}$. Patients with $\mathrm{CD}$ were considered as having acute $\mathrm{CD}$ (ACD) associated with brain hemorrhage if they met all of the following criteria: (1) accompanied by ECG change and abnormal cardiac troponin I (TnI) level, (2) no previous history of cardiac disease, and (3) wall motion abnormality extending beyond a single coronary arterial distribution. Otherwise, LV dysfunction was considered as other $\mathrm{CD}(\mathrm{OCD})$ unrelated to brain hemorrhage. We further classified ACD into 4 morphologic types according to the pattern of RWMA on echocardiography (Figure 2): (1) apical type (TTC pattern) showing apical or apical and mid-ventricular hypokinesia and normal or hyperkinetic motion of the basal wall, (2) mid-ventricular type showing mid-ventricular hypokinesia and preserved wall motion of the apical and basal
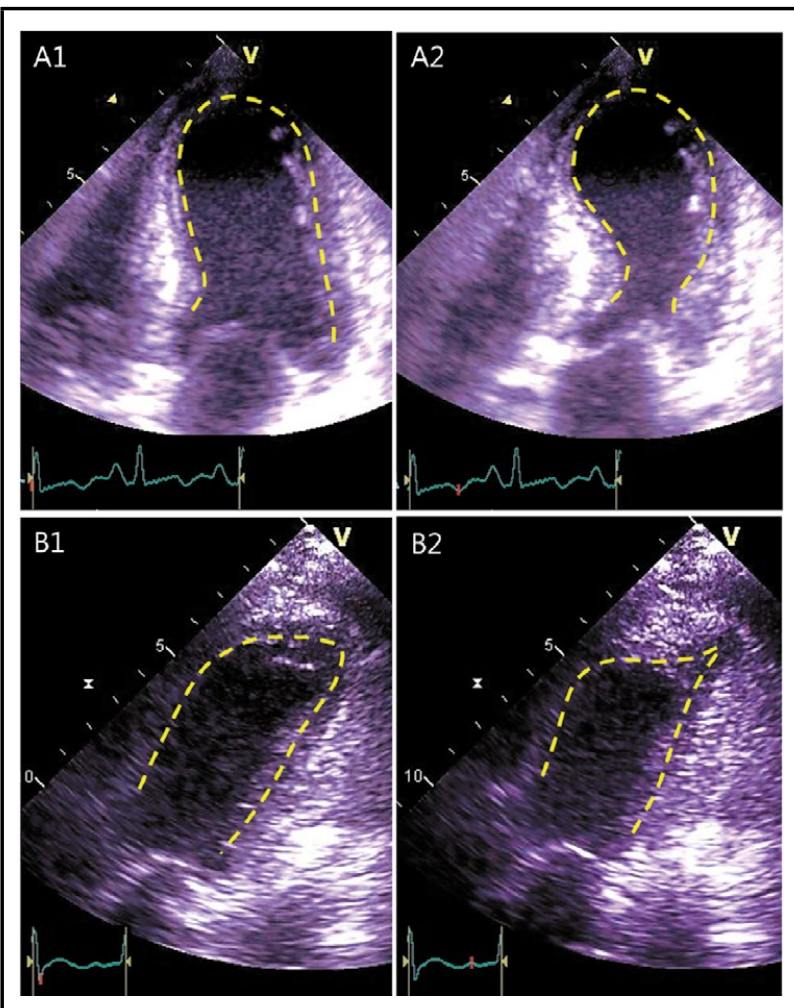

Figure 2. Examples of 2 different types of acute cardiac dysfunction. $(\mathbf{A} 1,2)$ Images captured at end-diastole and endsystole show the typical type of apical ballooning pattern. $(B 1,2)$ Images captured at end-diastole and end-systole show the reverse type with mid and basal hypokinesia.

wall, (3) reverse type (inverted TTC pattern) showing hyperkinesia of the apical wall and hypokinesia of the basal or basal and mid-ventricular wall, and (4) global type showing global hypokinesia of the LV. LV hypertrophy (LVH) was defined if the LV mass index was $>115 \mathrm{~g} / \mathrm{m}^{2}$ for men, and $>95 \mathrm{~g} / \mathrm{m}^{2}$ for women. On initial assessment, the patient's consciousness was scored using the Glasgow coma scale (GCS) on a scale of 3-15 and mentation was classified as alert, drowsy, stupor, semi-coma or coma. 


\begin{tabular}{|c|c|c|c|}
\hline & $\begin{array}{c}\text { Non-ACD } \\
(n=193)\end{array}$ & $\begin{array}{c}\text { ACD } \\
(n=15)\end{array}$ & $P$ value \\
\hline Age (years) & $59 \pm 15$ & $62 \pm 12$ & 0.488 \\
\hline Male, n (\%) & $115(59.6)$ & 8 (53.3) & 0.635 \\
\hline Systolic BP, mmHg & $166 \pm 38$ & $153 \pm 37$ & 0.312 \\
\hline Diastolic BP, mmHg & $96 \pm 21$ & $91 \pm 16$ & 0.690 \\
\hline Heart rate, beats/min & $84 \pm 19$ & $89 \pm 26$ & 0.594 \\
\hline \multicolumn{4}{|l|}{ Hemorrhage type, n (\%) } \\
\hline T-brain hemorrhage & $60(31.1)$ & $4(26.7)$ & 0.721 \\
\hline $\mathrm{S}-\mathrm{ICH}$ & $90(46.6)$ & $5(33.3)$ & 0.319 \\
\hline S-SAH & $33(17.1)$ & $2(13.3)$ & 0.707 \\
\hline S-SDH & $7(3.6)$ & $1(6.7)$ & 0.456 \\
\hline S-IVH & $3(1.6)$ & $3(20.0)$ & 0.005 \\
\hline Mentation (stupor or coma), n (\%) & $67(34.7)$ & $10(66.7)$ & 0.014 \\
\hline GCS $^{*}$ & $11(7-14)$ & $8(3-13)$ & 0.109 \\
\hline \multicolumn{4}{|l|}{ Medical history, $\mathrm{n}(\%)$} \\
\hline Hypertension & $64(33.2)$ & $5(33.3)$ & 0.999 \\
\hline Diabetes & $31(16.1)$ & $2(13.3)$ & 0.999 \\
\hline Prior stroke & $18(9.3)$ & $1(6.7)$ & 0.592 \\
\hline Prior heart disease & $13(6.7)$ & $0(0)$ & 0.299 \\
\hline Smoking & $46(23.8)$ & $4(26.7)$ & 0.805 \\
\hline \multicolumn{4}{|l|}{ Laboratory findings } \\
\hline Total cholesterol, mg/dl & $166 \pm 43$ & $165 \pm 47$ & 0.902 \\
\hline Creatinine, mg/dl & $0.9 \pm 0.8$ & $0.9 \pm 0.2$ & 0.412 \\
\hline CK-MB, ng/ml & $7.6 \pm 19.2$ & $8.3 \pm 9.4$ & 0.028 \\
\hline $\mathrm{Tnl}, \mathrm{ng} / \mathrm{ml}$ & $0.05 \pm 0.13$ & $0.78 \pm 1.72$ & $<0.001$ \\
\hline NT-proBNP, pg/ml & $659 \pm 1,326$ & $4,357 \pm 8,041$ & 0.046 \\
\hline Neurosurgery, n (\%) & $106(54.9)$ & $11(73.3)$ & 0.166 \\
\hline In-hospital death, n (\%) & $27(14.0)$ & $9(60.0)$ & $<0.001$ \\
\hline
\end{tabular}

${ }^{*}$ Expressed as median with interquartile range. ACD, acute cardiac dysfunction; BP, blood pressure; GCS, Glasgow coma score; ICH, intracranial hemorrhage; IVH, intraventricular hemorrhage; S-, spontaneous; SAH, subarachnoid hemorrhage; SDH, subdural hemorrhage; T-, traumatic; Tnl, troponin I.

\section{Echocardiography and Other Tests}

Comprehensive echocardiographic evaluations including 2D echocardiography and color and tissue Doppler studies were performed for each patient according to the study protocol using a Vivid 7, Vivid E9, or Vivid I device (GE Vingmed, Horten, Norway). Portable echocardiography was performed for patients who were not able to be transported to the echocardiographic laboratory from the NSICU for various reasons, such as mechanical ventilation or hemodynamic instability. RWMA was evaluated and scored by visual assessment according to the established guideline of the American Society of Echocardiography by an experienced echocardiographer who was unaware of the clinical findings of the patients. ${ }^{15}$ LVEF was evaluated by modified Simpson's method. LV mass was estimated using the Devereux formula and indexed to body surface area. ${ }^{16}$ Both TnI and creatine kinase (CK)-MB were measured with a chemiluminescent immunoassay (Beckman Coulter, Fullerton, CA, USA) on the day of admission. TnI elevation was defined as $>0.04 \mathrm{ng} / \mathrm{ml}$ by local clinical criteria. NT-proBNP was measured with a chemiluminescence enzyme immunoassay (Mitsubishi Chemical Medience Corp, Tokyo, Japan) and was considered elevated if $>125 \mathrm{pg} / \mathrm{ml}$ for patients under the age of 75 years and $>450 \mathrm{pg} / \mathrm{ml}$ for patients older than 75 years by local clinical criteria. 12-lead ECGs were obtained on the day of admission. A cardiologist analyzed the ECGs by manually measuring QT intervals and evaluated ST-segment depression or elevation and T wave inversion. QTc intervals were calculated using the Bazett correction. In the cases of atrial arrhythmias, intervals were averaged over 5 beats. QT interval prolongation was defined if QTc exceeded $470 \mathrm{~ms}$.

\section{Statistical Analysis}

Continuous variables are expressed as mean \pm standard deviation or median (interquartile range [IQR]). Categorical variables are expressed as number and percentage. The $\chi^{2}$ or Fisher's exact test was used for comparison of categorical variables, and the independent t-test or Mann-Whitney test was used for continuous variables according to the results of a normality test. Univariate logistic regression analyses were carried out for all clinical, laboratory and echocardiographic variables. For multivariate logistic regression analyses, variables with significant $\mathrm{P}$ values on univariate analyses were included in order to identify the independent predictors of inhospital death. Statistical analyses were performed using SPSS 21.0 software (IBM, Inc, Chicago, IL, USA) and P<0.05 was regarded as significant.

\section{Results}

\section{Clinical Characteristics}

During the study period, data for 208 patients (age: $59 \pm 15$ years, 123 men) with acute brain hemorrhage were collected. 
All the patients had undergone ECG, routine laboratory tests including cardiac enzymes, and echocardiography according to the study protocol. Portable echocardiography was performed for $71(34.1 \%)$ patients. A total of $15(7.2 \%)$ patients (age: $62 \pm 12$ years, 8 men) were diagnosed with ACD based on medical history, ECG, cardiac enzymes, and echocardiography (Figure 1); 9 (4.3\%) patients were diagnosed with OCD, and $184(88.5 \%)$ patients had no CD. Among the patients with ACD, 9 died in hospital $(60.0 \%)$ cases, while $1(11.1 \%)$ patient with OCD and $26(14.1 \%)$ patients without CD died during hospitalization. The clinical characteristics presented in Table 1 were compared between the ACD group and the non-ACD group. There were no significant differences in age, sex, blood pressure, heart rate or medical history between the 2 groups. In terms of hemorrhage type, spontaneous intraventricular hemorrhage was seen more frequently in the ACD group than in the non-ACD group (20.0\% vs. $1.6 \%, \mathrm{P}=0.005)$ and other types of hemorrhage were not different between the groups. More patients in the ACD group had worse mentation evident as stupor, semi-coma, or coma $(66.7 \%$ vs. $34.7 \%, \mathrm{P}=0.014)$, but the GCS was not significantly different between the groups. In the laboratory findings, CK-MB, TnI, and NT-proBNP levels were more elevated in the ACD group compared with the non-ACD group (Table 1). The proportion of patients who underwent neurosurgery during hospitalization was not different in the 2 groups. In the ACD group, in-hospital death occurred more frequently $(60.0 \%$ vs. $14.0 \%, \mathrm{P}<0.001)$.

\section{Cardiac Abnormalities}

Observed abnormalities in cardiac evaluation of the total patient group are summarized in Table 2 . In the analysis of the admission ECG, 19 (9.2\%) patients showed ST-segment elevation and $11(5.3 \%)$ patients showed ST-segment depression or $\mathrm{T}$ wave abnormality. QT interval prolongation was observed in $95(45.7 \%)$ patients. In the initial laboratory tests, $47(23.3 \%)$ patients had elevated TnI level and $123(59.1 \%)$ patients showed an abnormal NT-proBNP level. On the echocardiographic examination, 89 (42.8\%) cases had LVH and 24 (11.5\%) patients showed LV systolic dysfunction with RWMA or global hypokinesia. Among them, 15 (7.2\%) patients were classified as having ACD and $9(4.3 \%)$ patients as having

\begin{tabular}{|lc|}
\hline \multicolumn{2}{|c|}{ Table 2. Observed Cardiac Abnormality in the Study } \\
Patients With Acute Brain Hemorrhage ( $\mathbf{n = 2 0 8 )}$ \\
$\quad$ Abnormal finding & $\mathbf{n}(\%)$ \\
Electrocardiogram & \\
ST-segment elevation & $19(9.2)$ \\
ST-segment depression or T wave abnormality & $11(5.3)$ \\
QT interval prolongation & $95(45.7)$ \\
Laboratory test & \\
Troponin-I elevation & $47(23.3)$ \\
NT-proBNP elevation & $123(59.1)$ \\
Echocardiography & \\
LV hypertrophy & $89(42.8)$ \\
LV systolic dysfunction & $24(11.5)$ \\
\hline
\end{tabular}

OCD by the study definitions. Table 3 shows the characteristics of 15 patients with ACD and Table S1 shows characteristics of the 9 patients with OCD. Among the 15 patients with ACD, TnI level on admission was elevated in 12 patients, but 3 patients who had initially normal TnI levels showed TnI elevation on subsequent tests. Four patients initially had normal levels of NT-proBNP. Their LVEF ranged widely [ $48.0 \%$ (IQR, 30.5-49.6)]. The 15 patients also showed various morphologic types of RWMA: 6 (40.0\%) patients showed the reverse type and $4(26.7 \%)$ patients showed the apical type. The other $3(20.0 \%)$ and $2(13.3 \%)$ patients showed global hypokinesia and mid-ventricular hypokinesia, respectively. Therefore, 8 patients had the apex-sparing pattern of LV dysfunction and 7 patients had an apex-affected pattern (mean age, $57 \pm 12.2$ vs. $67 \pm 10.7$, respectively, $\mathrm{P}=0.094$ ).

\section{In-Hospital Mortality Rate}

A total of 36 patients died while hospitalized. Of them, 30 (8 in the ACD group, 22 in the non-ACD group) died from a neurogenic condition caused by acute brain hemorrhage. Among the other 6 patients, 2 ( 1 each in the 2 groups) died of sudden cardiac death and 1 patient died of heart failure; 2 patients died of uncontrolled sepsis and 1 patient died of aspiration pneu-

\begin{tabular}{|c|c|c|c|c|c|c|c|c|c|c|c|c|}
\hline $\begin{array}{c}\text { Case } \\
\text { no. }\end{array}$ & Sex & $\begin{array}{c}\text { Age } \\
\text { (years) }\end{array}$ & $\begin{array}{l}\text { Hemorrhage } \\
\text { type }\end{array}$ & $\begin{array}{l}\text { Admit } \\
\text { GCS }\end{array}$ & $\begin{array}{l}\text { Admit } \\
\text { Tnl }\end{array}$ & $\begin{array}{c}\text { Admit } \\
\text { NT-proBNP }\end{array}$ & EF & $\begin{array}{l}\text { Morphologic } \\
\text { type }\end{array}$ & ECG & $\begin{array}{c}\text { Prolonged } \\
\text { QTC }\end{array}$ & Surgery & Death \\
\hline 1 & M & 33 & S-IVH & 3 & 6.71 & 151 & 20.5 & Reverse & ST elevation & No & Yes & Yes \\
\hline 2 & $\mathrm{~F}$ & 54 & S-IVH & 3 & 0.08 & 55.4 & 30.6 & Reverse & ST depression & Yes & Yes & Yes \\
\hline 3 & $\mathrm{~F}$ & 79 & $\mathrm{~S}-\mathrm{ICH}$ & 15 & 0.91 & 2,668 & 48.8 & Apical & $\mathrm{T}$ wave inversion & Yes & No & No \\
\hline 4 & M & 66 & $\mathrm{~S}-\mathrm{ICH}$ & 4 & 0.11 & 457 & 49.5 & Reverse & ST elevation & Yes & Yes & Yes \\
\hline 5 & $\mathrm{~F}$ & 53 & S-SAH & 7 & 0.05 & 6,125 & 51.4 & Reverse & ST depression & Yes & No & No \\
\hline 6 & M & 78 & S-SDH & 8 & 0.05 & 7,219 & 48.1 & Apical & Flat T wave & Yes & Yes & No \\
\hline 7 & M & 59 & T-SDH & 14 & 0.05 & 389 & 48.0 & Global & ST depression & Yes & Yes & No \\
\hline 8 & $\mathrm{~F}$ & 75 & $\mathrm{~S}-\mathrm{ICH}$ & 3 & 0.14 & 16.2 & 30.5 & Apical & ST elevation & No & Yes & Yes \\
\hline 9 & $\mathrm{~F}$ & 55 & T-SDH & 9 & 0.03 & 394 & 28.3 & Mid-ventricular & Flat T wave & Yes & Yes & Yes \\
\hline 10 & M & 66 & $\mathrm{~S}-\mathrm{ICH}$ & 13 & 0.00 & 115 & 44.1 & Global & Flat T wave & Yes & Yes & Yes \\
\hline 11 & $\mathrm{~F}$ & 74 & S-IVH & 13 & 0.08 & 423 & 50.4 & Mid-ventricular & $\mathrm{T}$ wave inversion & Yes & No & No \\
\hline 12 & $\mathrm{~F}$ & 54 & S-SAH & 3 & 1.42 & 10,005 & 50.3 & Reverse & Flat T wave & No & No & Yes \\
\hline 13 & M & 50 & $\mathrm{~S}-\mathrm{ICH}$ & 3 & 0.06 & 2,989 & 19.0 & Global & ST elevation & Yes & Yes & Yes \\
\hline 14 & M & 65 & T-SDH & 13 & 0.00 & 116 & 49.6 & Reverse & ST elevation & No & Yes & No \\
\hline 15 & M & 65 & T-SDH & 15 & 16.03 & $>30,000$ & 38.1 & Apical & ST depression & Yes & Yes & Yes \\
\hline
\end{tabular}

EF, ejection fraction. Other abbreviations as in Table 1. 


\begin{tabular}{|c|c|c|c|c|c|c|}
\hline \multirow{2}{*}{ Variable } & \multicolumn{3}{|c|}{ Univariate analysis } & \multicolumn{3}{|c|}{ Multivariate analysis } \\
\hline & OR & $95 \% \mathrm{Cl}$ & $P$ value & OR & $95 \% \mathrm{Cl}$ & $P$ value \\
\hline Age & 1.00 & $0.97-1.02$ & 0.677 & & & \\
\hline Female (vs. male) sex & 0.79 & $0.37-1.65$ & 0.524 & & & \\
\hline Systolic BP & 1.01 & $1.00-1.02$ & 0.066 & & & \\
\hline T- (vs. S-) hemorrhage & 1.15 & $0.54-2.48$ & 0.714 & & & \\
\hline Heart rate & 1.02 & $1.00-1.03$ & 0.090 & & & \\
\hline GCS & 0.77 & $0.69-0.85$ & $<0.001$ & 0.77 & $0.68-0.87$ & $<0.001$ \\
\hline Creatinine & 1.19 & $0.83-1.70$ & 0.357 & & & \\
\hline Total cholesterol & 0.99 & $0.98-1.00$ & 0.009 & 0.99 & $0.98-1.00$ & 0.017 \\
\hline Tnl & 11.02 & $2.21-55.11$ & 0.003 & 2.41 & $0.26-22.19$ & 0.437 \\
\hline Neurosurgery & 2.73 & $1.21-6.15$ & 0.015 & 1.17 & $0.44-3.14$ & 0.749 \\
\hline Acute cardiac dysfunction & 9.22 & $3.04-27.99$ & $<0.001$ & 8.02 & $1.76-36.46$ & 0.007 \\
\hline
\end{tabular}

$\mathrm{Cl}$, confidence interval; OR, odds ratio. Other abbreviations as in Tables 1,3.

monia. In the univariate analysis, GCS, total cholesterol, TnI, neurosurgery, and ACD were significant predictors for inhospital death (Table 4). The other variables, including age, sex, systolic blood pressure, hemorrhagic type, heart rate, and creatinine, were not significant predictors in the univariate analysis. Medical history of hypertension, diabetes, prior stroke, prior heart disease, and smoking was not significant for predicting in-hospital death (data not shown). In the multivariate analysis, GCS (odds ratio [OR] $0.77,95 \%$ confidence interval [CI] 0.68-0.87, $\mathrm{P}<0.001$ ), total cholesterol (OR 0.99, 95\% CI 0.98-1.00, P=0.017) and ACD (OR 8.02, 95\% CI $1.76-36.46, \mathrm{P}=0.007)$ were independent risk factors for inhospital death.

\section{Discussion}

This prospectively enrolled study of patients with acute brain hemorrhage showed that ACD was related to acute brain hemorrhage in $7 \%$ and early TnI elevation in $23 \%$ of the patients. Of the 15 cases of ACD, 8 were males $(53 \%)$ and $8(53 \%)$ patients had the apex-sparing pattern of LV wall motion abnormality. Patients with ACD had a high in-hospital mortality rate independent of initial GCS. These results suggest that ACD related to brain hemorrhage has different clinical manifestations from the typical TTC pattern in regards to nonfemale dominance, more frequent apex-sparing RWMA and high rate of in-hospital death. In addition, ACD occurred not only in patients with SAH but also in patients with other types of acute brain hemorrhage with similar proportions.

To the best of our knowledge, our study is the first prospective study to investigate ACD in patients with all types of acute brain hemorrhage. Hitherto, there have been no data concerning the incidence of ACD in this population. The incidence of LV dysfunction and TnI elevation in patients with SAH has been reported in several studies. Hravnak et al reported the incidence of LV dysfunction and TnI elevation as $9 \%$ and $31 \%$, respectively, in a study for 204 patients with SAH. ${ }^{4}$ Another prospective study of 173 patients with SAH reported that $28 \%$ regional or global LV systolic dysfunction and $23 \%$ TnI elevation. ${ }^{3}$ Khush et al also reported RWMA in $27 \%$ of patients with $\mathrm{SAH},{ }^{17}$ and Tung et al reported that $20 \%$ of 223 patients with SAH had TnI elevation. ${ }^{18}$ The former study ${ }^{4}$ showed a comparable incidence with our results, but the latter study ${ }^{17}$ showed a much higher incidence of LV dysfunction than in ours. The latter study conducted 3 serial echocardio- graphic examinations and included any RWMA found in any of the 3 echocardiographic examinations, which may have contributed to the high incidence of LV dysfunction in their patients. The similar proportion of patients having early TnI elevation in the studies, including our study, may support this possibility. On the other hand, $4(6 \%)$ of 64 patients with traumatic brain hemorrhage showed ACD in the present study, which was almost the same proportion as observed for patients with SAH [2 $(6 \%)$ cases in 35 patients]. CD occurring with traumatic brain hemorrhage has been rarely reported. Busl et al reported that troponin elevation was noted in $9(8 \%)$ of 114 patients with SDH and they concluded that myocardial injury was infrequent in patients with SDH. ${ }^{19}$ In the present study, however, 13 (21\%) of 61 patients with SDH (53 traumatic and 8 spontaneous SDH cases) had initial TnI elevation and the proportion was compatible with that in patients with SAH: 9 (26\%) of 35 patients with SAH had TnI elevation.

TTC is well-known for its uneven sex distribution. A recent large study reported a female-to-male ratio of 9:1 in 1,750 patients with TTC. ${ }^{20}$ Female predominance with a similar ratio was also reported in other studies..$^{21,22}$ However, the femaleto-male ratio of LV dysfunction in patients with $\mathrm{SAH}$ has varied in several studies and female predominance does not seem to be as clear as that found with TTC. A previous study of SAH patients reported that $31 \%$ of all female patients and $39 \%$ of all male patients had TnI elevation, and $11 \%$ of all female patients and $4 \%$ of all male patients had RWMA. ${ }^{4}$ Another study of patients with SAH reported that $27 \%$ and $26 \%$ of female and male patients, respectively, showed RWMA, and another study reported $24 \%$ and $9 \%$ of female and male patients, respectively, showed TnI elevation. ${ }^{17,18}$ The current study reported proportions of TnI elevation as $20 \%$ and $24 \%$ of female and male patients, respectively, and respective proportions of RWMA as $8 \%$ and $7 \%$. The collective data indicate that $\mathrm{CD}$ in patients with brain hemorrhage seems to occur in both sexes at a similar rate. Why the sex distribution is different from that of TTC is unclear at this point.

Along with female predominance, TTC also features apical ballooning-type RWMA of the LV. Recent studies including a large number of patients with TTC report apical ballooningtype RWMA in $82 \%$ and $92 \%$, respectively. ${ }^{20,23}$ Interestingly, NSC seems to have some differences in the pattern of RWMA of the LV. Two previous studies that investigated LV dysfunction in patients with SAH reported that the apex-sparing pattern of RWMA was observed in $49 \%$ and $58 \%$, respectively. 4,17 
Another study reported that apical involvement of RWMA in SAH patients was evident in $23-40 \%$ of the patients. ${ }^{3}$ Similarly, the current study showed that only 4 (27\%) of 15 patients with ACD had the apical type of RWMA. Excluding 3 more patients with global hypokinesia, 8 (53\%) patients showed the apex-sparing pattern of RWMA, which was similar to previous studies that included patients with SAH. In TTC, the reverse or inverted variant has been reported to be more frequently present at a younger age and to be always associated with triggering stress. ${ }^{24,25}$ One study of LV dysfunction after $\mathrm{SAH}$ concluded that younger age and anterior aneurysm position were independent predictors of this apex-sparing pattern. ${ }^{17}$ The trend of young age in patients with apex-sparing LV dysfunction was seen in this study despite statistical insignificance. From these results, young age and physical stress, especially neurogenic stress, seem to be more associated with the reverse or inverted pattern of LV dysfunction. Catecholamine cardiotoxicity has been recognized as the main pathophysiology explaining CD in both TTC and NSC.9,26,27 The various patterns of wall motion abnormality observed in TTC and NSC seem to be explained by the different distribution of sympathetic innervation and adrenergic receptors in the myocardium. Previous studies demonstrated a higher concentration of adrenoceptors in the apical myocardium compared with the mid or basal myocardium, whereas other studies showed a higher density of sympathetic nerve terminals in the basal myocardium compared with the apex..$^{28-31}$ This arrangement would allow balanced myocardial responses to sympathetic activation under low and medium levels. ${ }^{26}$ At the highest (supraphysiological) level of sympathetic stimuli, however, a disturbance of the balance and a change in the adrenergic signaling pathways for negative inotropic effect have been reported, which might cause regional LV hypokinesia. ${ }^{32,33}$ Banki et al explained that the apex-sparing pattern of $\mathrm{LV}$ dysfunction in patients with SAH was caused by a relative paucity of sympathetic nerve terminals in the apex. ${ }^{3} \mathrm{We}$ also suspect that the LV basal segments having more sympathetic nerve endings might be more vulnerable to catecholamine toxicity under the conditions of neurogenic stress whereas the LV apex having more adrenoceptors might be more vulnerable to catecholamine toxicity under the conditions of general stress. Cimarelli et al reported that sympathetic function and glucose metabolism seem to be strictly correlated in the hypocontractile LV segments in patients with TTC. ${ }^{33}$ However, another small study using myocardial scintigraphy failed to show a significant difference in the sympathetic innervation between the apex-sparing and apex-affecting patterns of NSC in patients with $\mathrm{SAH} .{ }^{17}$ The precise pathophysiology for the different wall motion abnormalities between TTC and NSC needs further study.

In this study, patients with $\mathrm{ACD}$ and acute brain hemorrhage had a high in-hospital mortality rate $(60 \%)$, which was much higher than the in-hospital mortality rates of $14 \%$ or $11 \%$ in the study patients without CD or with OCD, respectively. Regarding TTC, previous studies reported in-hospital mortality rates of $8.4 \%{ }^{23}$ and $16 \%,,^{34}$ and mortality per patientyear of $5.6 \% .{ }^{20}$ Our data showed an in-hospital mortality rate of $6.7 \%$ in 15 patients diagnosed with TTC according to Mayo clinic criteria during the same study period in our hospital (The characteristics of 15 patients are shown in Table S2). ${ }^{35,36}$ Therefore, patients with ACD and acute brain hemorrhage seem to have a poorer prognosis than patients with acute brain hemorrhage but with ACD or patients with generic TTC. Another study involving SAH patients reported a poor outcome in patients with $\mathrm{TnI}$ elevation compared with patients without $\mathrm{TnI}$ elevation (37\% vs. $19 \%) .{ }^{4}$ In addition to $\mathrm{SAH}$, TnI elevation in patients with ICH or ischemic stroke was also reported to be significantly associated with poor in-hospital outcome. ${ }^{37}$ Because poor neurologic condition is associated with the development of $\mathrm{CD}, 3,4,18$ the poor outcome in patients with neurocardiac injury is caused mainly by the underlying neurologic condition. Consistent with our findings, however, several studies have shown that poorer outcomes in patients with neurocardiac injury are independent of SAH severity. ${ }^{38,39}$ Furthermore, in the current study, LV dysfunction on echocardiography was a more powerful predictor than $\mathrm{TnI}$ elevation for in-hospital death.

\section{Study Limitations}

Firstly, the study patients were enrolled in a single center and for a relatively short duration, and the number of patients with ACD was too small to characterize the different types of ACD and to show a statistically significant difference among different types of ACD. Secondly, because we included heterogeneous types of brain hemorrhage we could not classify the patients by the severity of brain hemorrhage and could not investigate the relationship between severity of brain hemorrhage and incidence of ACD. Instead, we analyzed the effect of ACD on short-term outcome adjusted for initial GCS. Thirdly, we could not show long-term follow-up data because we only followed the patients until hospital discharge or death. As other limitations, we did not perform serial echocardiography for all patients but only early admission echocardiography, so we may have missed cases of ACD developing later after admission and were unable to discern the changes of cardiac function. Coronary angiography was not performed in study patients, which prevented us from defining our study patients as having stress cardiomyopathy according to the Mayo clinic criteria. ${ }^{35}$ Moreover, the classification of ACD and OCD in this study might be incomplete and some patients may have had both components.

\section{Conclusions}

$\mathrm{ACD}$ associated with acute brain hemorrhage was observed in $7 \%$ of the present study patients. In comparison with TTC, ACD in patients with brain hemorrhage occurred in both men and women at a similar rate and showed an apex-sparing pattern of LV systolic dysfunction at a higher rate. In addition, patients with ACD had a higher in-hospital mortality rate, which was independent of their initial GCS.

\section{References}

1. Burch GE, Meyers R, Abildskov JA. A new electrocardiographic pattern observed in cerebrovascular accidents. Circulation 1954; 9: 719-723.

2. Parekh N, Venkatesh B, Cross D, Leditschke A, Atherton J, Miles W, et al. Cardiac troponin I predicts myocardial dysfunction in aneurysmal subarachnoid hemorrhage. J Am Coll Cardiol 2000; 36: $1328-1335$.

3. Banki N, Kopelnik A, Tung P, Lawton MT, Gress D, Drew B, et al. Prospective analysis of prevalence, distribution, and rate of recovery of left ventricular systolic dysfunction in patients with subarachnoid hemorrhage. J Neurosurg 2006; 105: 15-20.

4. Hravnak M, Frangiskakis JM, Crago EA, Chang Y, Tanabe M, Gorcsan J 3rd, et al. Elevated cardiac troponin I and relationship to persistence of electrocardiographic and echocardiographic abnormalities after aneurysmal subarachnoid hemorrhage. Stroke 2009; 40: $3478-3484$.

5. Rahimi AR, Katayama M, Mills J. Cerebral hemorrhage: Precipitating event for a tako-tsubo-like cardiomyopathy? Clin Cardiol 2008; 31: $275-280$.

6. Murthy SB, Shah S, Venkatasubba Rao CP, Suarez JI, Bershad EM. 
Clinical characteristics of myocardial stunning in acute stroke. J Clin Neurosci 2014; 21: 1279-1282.

7. McLeod AA, Neil-Dwyer G, Meyer CH, Richardson PL, Cruickshank J, Bartlett J. Cardiac sequelae of acute head injury. Br Heart J 1982; 47: $221-226$

8. Lee VH, Oh JK, Mulvagh SL, Wijdicks EF. Mechanisms in neurogenic stress cardiomyopathy after aneurysmal subarachnoid hemorrhage. Neurocrit Care 2006; 5: 243-249.

9. Guglin M, Novotorova I. Neurogenic stunned myocardium and takotsubo cardiomyopathy are the same syndrome: A pooled analysis. Congest Heart Fail 2011; 17: 127-132.

10. Wittstein IS, Thiemann DR, Lima JA, Baughman KL, Schulman SP, Gerstenblith G, et al. Neurohumoral features of myocardial stunning due to sudden emotional stress. N Engl J Med 2005; 352: 539-548.

11. Masuda T, Sato K, Yamamoto S, Matsuyama N, Shimohama T, Matsunaga A, et al. Sympathetic nervous activity and myocardial damage immediately after subarachnoid hemorrhage in a unique animal model. Stroke 2002; 33: 1671-1676.

12. Elrifai AM, Bailes JE, Shih SR, Dianzumba S, Brillman J. Characterization of the cardiac effects of acute subarachnoid hemorrhage in dogs. Stroke 1996; 27: 737-741; discussion 741-742.

13. Cruickshank JM, Neil-Dwyer G, Degaute JP, Hayes Y, Kuurne T, Kytta J, et al. Reduction of stress/catecholamine-induced cardiac necrosis by beta 1-selective blockade. Lancet 1987; 2: 585-589.

14. Kawai S, Kitabatake A, Tomoike H. Guidelines for diagnosis of takotsubo (ampulla) cardiomyopathy. Circ J 2007; 71: 990-992.

15. Lang RM, Badano LP, Mor-Avi V, Afilalo J, Armstrong A, Ernande $\mathrm{L}$, et al. Recommendations for cardiac chamber quantification by echocardiography in adults: An update from the American Society of Echocardiography and the European Association of Cardiovascular Imaging. J Am Soc Echocardiogr 2015; 28: 1-39.e14.

16. Devereux RB, Alonso DR, Lutas EM, Gottlieb GJ, Campo E, Sachs I, et al. Echocardiographic assessment of left ventricular hypertrophy: Comparison to necropsy findings. Am J Cardiol 1986; 57: $450-458$

17. Khush K, Kopelnik A, Tung P, Banki N, Dae M, Lawton M, et al. Age and aneurysm position predict patterns of left ventricular dysfunction after subarachnoid hemorrhage. J Am Soc Echocardiogr 2005; 18: $168-174$.

18. Tung P, Kopelnik A, Banki N, Ong K, Ko N, Lawton MT, et al. Predictors of neurocardiogenic injury after subarachnoid hemorrhage. Stroke 2004; 35: 548-551.

19. Busl KM, Raju M, Ouyang B, Garg RK, Temes RE. Cardiac abnormalities in patients with acute subdural hemorrhage. Neurocrit Care 2013; 19: 176-182.

20. Templin C, Ghadri JR, Diekmann J, Napp LC, Bataiosu DR, Jaguszewski M, et al. Clinical features and outcomes of takotsubo (stress) cardiomyopathy. N Engl J Med 2015; 373: 929-938.

21. Sharkey SW, Windenburg DC, Lesser JR, Maron MS, Hauser RG, Lesser JN, et al. Natural history and expansive clinical profile of stress (tako-tsubo) cardiomyopathy. J Am Coll Cardiol 2010; 55: $333-341$.

22. Schneider B, Athanasiadis A, Stollberger C, Pistner W, Schwab J, Gottwald U, et al. Gender differences in the manifestation of takotsubo cardiomyopathy. Int J Cardiol 2013; 166: 584-588.

23. Aizawa K, Suzuki T. Takotsubo cardiomyopathy: Japanese perspective. Heart Fail Clin 2013; 9: 243-247, x.

24. Ramaraj R, Movahed MR. Reverse or inverted takotsubo cardiomyopathy (reverse left ventricular apical ballooning syndrome) presents at a younger age compared with the mid or apical variant and is always associated with triggering stress. Congest Heart Fail 2010; 16: $284-286$.

25. Song BG, Chun WJ, Park YH, Kang GH, Oh J, Lee SC, et al. The clinical characteristics, laboratory parameters, electrocardiographic, and echocardiographic findings of reverse or inverted takotsubo cardiomyopathy: Comparison with mid or apical variant. Clin Cardiol 2011; 34: 693-699.

26. Wright PT, Tranter MH, Morley-Smith AC, Lyon AR. Pathophysiology of takotsubo syndrome: Temporal phases of cardiovascular responses to extreme stress. Circ J 2014; 78: 1550-1558.

27. Ono R, Falcao LM. Takotsubo cardiomyopathy systematic review: Pathophysiologic process, clinical presentation and diagnostic approach to Takotsubo cardiomyopathy. Int J Cardiol 2016; 209: 196-205.

28. Paur H, Wright PT, Sikkel MB, Tranter MH, Mansfield C, O'Gara $\mathrm{P}$, et al. High levels of circulating epinephrine trigger apical cardiodepression in a beta2-adrenergic receptor/Gi-dependent manner: A new model of Takotsubo cardiomyopathy. Circulation 2012; 126: 697-706.

29. Mori H, Ishikawa S, Kojima S, Hayashi J, Watanabe Y, Hoffman JI, et al. Increased responsiveness of left ventricular apical myocardium to adrenergic stimuli. Cardiovasc Res 1993; 27: 192-198.

30. Kline RC, Swanson DP, Wieland DM, Thrall JH, Gross MD, Pitt B, et al. Myocardial imaging in man with I-123 meta-iodobenzylguanidine. J Nucl Med 1981; 22: 129-132.

31. Pierpont GL, DeMaster EG, Reynolds S, Pederson J, Cohn JN. Ventricular myocardial catecholamines in primates. J Lab Clin Med 1985; 106: $205-210$.

32. Lyon AR, Rees PS, Prasad S, Poole-Wilson PA, Harding SE. Stress (Takotsubo) cardiomyopathy: A novel pathophysiological hypothesis to explain catecholamine-induced acute myocardial stunning. Nat Clin Pract Cardiovasc Med 2008; 5: 22-29.

33. Cimarelli S, Sauer F, Morel O, Ohlmann P, Constantinesco A, Imperiale A. Transient left ventricular dysfunction syndrome: Pathophysiological bases through nuclear medicine imaging. Int J Cardiol 2010; 144: 212-218.

34. Lee PH, Song JK, Sun BJ, Choi HO, Seo JS, Na JO, et al. Outcomes of patients with stress-induced cardiomyopathy diagnosed by echocardiography in a tertiary referral hospital. J Am Soc Echocardiogr 2010; 23: 766-771.

35. Bybee KA, Kara T, Prasad A, Lerman A, Barsness GW, Wright RS, et al. Systematic review: Transient left ventricular apical ballooning: A syndrome that mimics ST-segment elevation myocardial infarction. Ann Intern Med 2004; 141: 858-865.

36. Scantlebury DC, Prasad A. Diagnosis of Takotsubo cardiomyopathy. Circ J 2014; 78: 2129-2139.

37. Sandhu R, Aronow WS, Rajdev A, Sukhija R, Amin H, D'Aquila K, et al. Relation of cardiac troponin I levels with in-hospital mortality in patients with ischemic stroke, intracerebral hemorrhage, and subarachnoid hemorrhage. Am J Cardiol 2008; 102: 632-634.

38. Schuiling WJ, Dennesen PJ, Tans JT, Kingma LM, Algra A, Rinkel GJ. Troponin I in predicting cardiac or pulmonary complications and outcome in subarachnoid haemorrhage. J Neurol Neurosurg Psychiatry 2005; 76: $1565-1569$.

39. Naidech AM, Kreiter KT, Janjua N, Ostapkovich ND, Parra A, Commichau C, et al. Cardiac troponin elevation, cardiovascular morbidity, and outcome after subarachnoid hemorrhage. Circulation 2005; 112: 2851-2856.

\section{Supplementary Files}

Supplementary File 1

Table S1. Characteristics of 9 patients with cardiac dysfunction unrelated to brain hemorrhage

Table S2. Clinical characteristics of 15 patients diagnosed with takotsubo cardiomyopathy according to Mayo Clinic criteria during the same study period in the same hospital

Please find supplementary file(s);

http://dx.doi.org/10.1253/circj.CJ-16-0395 